\title{
Engagement with perinatal mental health services: a cross-sectional questionnaire survey
}

\author{
Alice Ayres ${ }^{1,4^{*}}$ D, Renee Chen ${ }^{1,4}$, Tracey Mackle ${ }^{2}$, Emma Ballard ${ }^{5,7} \mathbb{D}$, Sue Patterson ${ }^{2,6}$ (D), George Bruxner ${ }^{2,4}$ (D) and
} Alka Kothari ${ }^{3,4}$ (1)

\begin{abstract}
Background: Perinatal depression and/or anxiety disorders are undertreated pregnancy complications. This is partly due to low rates of engagement by women. This study aimed to identify barriers and facilitators to women accessing perinatal mental health services in an outer metropolitan hospital in Queensland, Australia.

Methods: Data was collected from pregnant women through a cross-sectional survey. Women rated the extent certain factors influenced their engagement. Respondents were separated into three groups: women who were not offered a referral to perinatal mental health services, women who were offered a referral but did not engage, and women who engaged.

Results: A total of 218 women participated. A response rate of $71 \%$ was achieved. $38.1 \%$ of participants did not believe themselves knowledgeable about mental illness in the perinatal period, and $14.7 \%$ did not recall being asked about their mental health during their pregnancy. Of those participants who recalled being asked about their mental health, 37.1\% were offered a referral. Of these, just over a third (36.2\%) accepted, and out of this group, 40\% attended an appointment. Regardless of referral and engagement status, the factors identified as influencing participant engagement were time restraints, lack of childcare support, and encouragement by family and health care professionals. Stigma was not identified as a barrier.

Conclusions: Perinatal mental health service engagement could be improved by health services: ensuring universal screening and actively engaging women in the process: assisting with childcare; improving appointment immediacy and accessibility; and educating health care professionals about their influence on women's engagement.
\end{abstract}

Keywords: Patient engagement, Perinatal care, Depression, Anxiety, Barrier, Facilitator

\section{Background}

Mental illnesses are among the most common morbidities affecting women during pregnancy and the post-partum period (the perinatal period) [1]. Antenatal depression and anxiety are particularly common, affecting up to one in ten, and one in five women respectively [2-4]. Antenatal women experiencing depression are at increased risk of obstetric complications including preterm birth, low neonatal birth weight, gestational hypertension, and perinatal

\footnotetext{
* Correspondence: alice.ayres@health.qld.gov.au

${ }^{1}$ Child and Youth Mental Health Service, Child Health Queensland, South

Brisbane, Queensland 4010, Australia

${ }^{4}$ Faculty of Medicine, University of Queensland, Brisbane, Queensland,

Australia

Full list of author information is available at the end of the article
}

infant and mother mortality [5]. Psychiatric morbidity is a leading contributing cause of maternal death in Australia, with approximately one in six maternal deaths due to suicide $[6,7]$. While effective treatment is available, women experiencing perinatal depression and/or anxiety (PD/A) are often reluctant to access mental health services and/or disclose mental health symptoms despite regular contact with health services $[8,9]$.

Research suggests that approximately half of women who screen positive for $\mathrm{PD} / \mathrm{A}$ attend for a specialist mental health assessment [8]. Studies in high-income countries, predominantly in the United States of America (USA) and the United Kingdom, have identified factors affecting engagement with perinatal mental health

(c) The Author(s). 2019 Open Access This article is distributed under the terms of the Creative Commons Attribution 4.0 International License (http://creativecommons.org/licenses/by/4.0/), which permits unrestricted use, distribution, and reproduction in any medium, provided you give appropriate credit to the original author(s) and the source, provide a link to the Creative Commons license, and indicate if changes were made. The Creative Commons Public Domain Dedication waiver (http://creativecommons.org/publicdomain/zero/1.0/) applies to the data made available in this article, unless otherwise stated. 
services (PMHS). These factors include time constraints, perceived stigma, cultural implications, women's inability to identify their symptoms, and the attitudes of family, friends, and healthcare professionals (HCP) [10-13]. Due to substantial contextual differences that exist between healthcare systems, the applicability of these identified factors in the Australian context requires further exploration. For example, in contrast to the USA, Australia provides free universal healthcare, and Australian national guidelines and policy requires health care facilities to complete mandatory universal screening for anxiety and depression during the perinatal period. Moreover, this policy has supported public education campaigns to increase public awareness of PD/A [14-16].

To date, there have been few studies examining factors influencing women's engagement with PMHS in Australia (summarised in Table 1). This study aimed to increase engagement with PMHS by identifying modifiable barriers and facilitators to women accessing PMHS following a referral from their antenatal obstetric service.

\section{Methods \\ Setting}

The study was conducted at a 270-bed public outer metropolitan hospital $(\mathrm{OMH})$ serving a socio-economically disadvantaged region in Queensland, Australia [25]. On the outskirts of the capital city, in a 'growth corridor', the catchment population of $\sim 151,000$ has relatively higher rates of hospital utilisation than Queensland residents generally [26].

Pregnant women residing in the OMH catchment can access free obstetrician-led outpatient antenatal care, regardless of their pregnancy risk profile. At the initial visit (7-14 weeks), service midwives routinely screen patients for symptoms of depression and anxiety, using the Edinburgh Postnatal Depression Scale (EPDS). As part of this process, women are provided written and verbal information about $\mathrm{PD} / \mathrm{A}$. Women who score $\geq 13$, and/or have a positive response to the item (ten) regarding thoughts of self-harm, are offered a referral to the local PMHS. When a referral is received, the PMHS arranges outreach assessment or appointments at the OMH. Engagement with PMHS is voluntary. Practice-based evidence (Mackle 2016, personal communication, 5th June) indicates that one-third of women who are referred to the local PMHS agree to make an initial appointment, and of these women, only one-third attend.

\section{Ethics approval}

The study was approved by the authorised certified $\mathrm{Hu}-$ man Research Ethics Committee (HREC/16/QPCH/237) and the site Research Governance office of the hospital. Before accessing the questionnaire, potential participants were provided verbal and written information by the study investigators and advised that completion of the questionnaire would imply consent for the use of the data for research purposes.

\section{Design}

A cross-sectional survey was conducted using a questionnaire designed specifically for this study. The questionnaire (additional file 1) was iteratively developed in several stages. Initially, a pool of items was generated based on a review of the literature (summarised in Table 1) and consultation with obstetricians, midwives, mental health clinicians, and psychiatrists with expert knowledge of the population of interest. The first section of the questionnaire contained items concerning participant demographic data, and their obstetric and mental health histories, specifically addressing depression and anxiety. The second section of the questionnaire invited participants to rate their self-reported mental health knowledge on a 5-point Likert scale and enquired as to their PMHS referral status and level of engagement. The third section of the questionnaire included items identifying potential barriers and facilitators to PMHS engagement. There were 22 items (11 items each for barriers and facilitators) and women were asked to rate, on a 3-point Likert scale, the extent to which these factors had influenced or would have influenced their engagement with PMHS. There was no free text option available and the questionnaire took a maximum of 5 minutes to complete.

A tree algorithm was utilised for the questionnaire, as depicted in Fig. 1. The three primary branches of the questionnaire were tailored for (1) women not offered referral to the PMHS (WNOR); (2) women offered referral to the PMHS who did not attend (WDNA); and (3) women who were offered a referral to the PMHS and attended (WA).

The questionnaire was piloted with ten women to assess face and content validity. Cognitive interviewing was used to explore interpretation and comprehensibility of each item. Adjustments were made to the general structure of the questionnaire, and the wording and sequence of items based on the feedback of this pilot group. The women on whom the questionnaire was piloted, appreciated the anonymous nature of the questionnaire and found the Google Forms format user-friendly.

\section{Participants}

Women receiving antenatal care at the hospital were eligible for participation if they were aged 18 years or older, attending their first medical antenatal appointment, and sufficiently fluent in English to complete the consent processes and questionnaire.

\section{Recruitment and data collection}

Recruitment for the study was time limited and occurred from February 2017 to July 2017. Convenience sampling 
Table 1 Summary of appraised studies that investigated barriers and facilitators to engagement with PMHS

\begin{tabular}{|c|c|c|}
\hline Author, year, country & Study type, sample & Main findings \\
\hline $\begin{array}{l}\text { Bilzta et al. } 2010 \text { [10] } \\
\text { Australia }\end{array}$ & $\begin{array}{l}\text { Qualitative study by focus groups, } n=40 \\
\text { postpartum women }\end{array}$ & $\begin{array}{l}\text { Findings suggest the lived experience of postnatal depression and } \\
\text { associated attitudes and beliefs result in significant barriers to } \\
\text { accessing help. Eight theme clusters were identified: expectations of } \\
\text { motherhood; not coping and fear of failure; stigma and denial; poor } \\
\text { mental health awareness and access; interpersonal support; baby } \\
\text { management; help-seeking and treatment experiences and relation- } \\
\text { ship with health professionals. }\end{array}$ \\
\hline
\end{tabular}

Button et al. 2017 [17] Metasynthesis of 24 studies

United Kingdom

Byatt et al. 2012 [18]

United States

Byatt et al. 2015 [9]

United States

Dennis et al. 2006 [11] Canada

Flynn et al. 2010 [12] United States

Goodman 2009 [13] United States

Highet et al. 2014 [19] Australia

Kim et al. 2010 [8]

United States

Kopelman et al. 2008 [20] Mixed methods approach, $n=1416$ United States

McCarthy. 2008 [21]

Australia
Qualitative study by face-to-face interview, $n=4$ groups of perinatal health care professionals

Systematic review of 17 studies

Systematic review of 40 qualitative studies

Qualitative study by semi-structured interviews, $n=23$

Quantitative study by cross sectional survey $n=509$ antenatal women

Qualitative study by interview, $n=28$ postpartum women

Mixed methods approach by telephone interview, $n=51$ perinatal women antenatal women

Qualitative study by interview, $n=15$ postpartum women
Three main themes affecting women's decision to seek help for perinatal distress: identifying a problem, the influence of healthcare professionals, and stigma.

Participants identified patient-, provider- and system-level barriers and facilitators to addressing perinatal depression. Provider-level barriers included lack of resources, skills and confidence needed to diagnose, refer and treat perinatal depression. Limited access to mental health care and resources were identified as system-level barriers.

Higher rates of mental health care use were associated with implementation of additional interventions, including resource provision to women, perinatal care provider training, on-site assessment, and access to mental health consultation for perinatal care providers compared to screening alone.

A common help-seeking barrier was women's inability to disclose their feelings, which was often reinforced by family members and health professionals' reluctance to respond to the mothers' emotional and practical needs. The lack of knowledge about postpartum depression or the acceptance of myths was a significant help-seeking barrier and rendered mothers unable to recognize the symptoms of depression. Significant health service barriers were identified.

Two broad themes influencing depression treatment usage emerged including practical and psychological factors. Among practical factors, women reported a strong preference for treatment provided in the obstetric clinic or in the home with a desire for a proactive referral process and flexible options for receiving treatment. Psychological factors included differing conceptualizations of depression, knowledge about severity and treatment and issues of stigma.

The greatest perceived potential barriers to treatment were lack of time $(65 \%)$, stigma $(43 \%)$, and childcare issues (33\%). Most women indicated a preference to receive mental health care at the obstetrics clinic, either from their obstetrics practitioner or from a mental health practitioner located at the clinic.

Particular symptoms of anxiety and depression develop in the context of the numerous changes inherent to the transition to motherhood and contribute to a common experience of frustration and loss. Symptoms were also associated with feelings of dissatisfaction with the pregnancy and motherhood experience.

Barriers to successful treatment linkage were identified the patient, provider, and system levels. Although 59\% of at-risk women accepted mental health referrals, only $27 \%$ ultimately engaged in treatment.

Results suggest that addressing financial and logistical barriers through changes in mental health services and policy will improve access to care for antenatal depression.

The majority of women interviewed had reached "crisis point" before they sought and received treatment. The stigma attached to an inability to cope and being a "bad mother" emerged as the main barrier to seeking help earlier. In addition, women were unable to differentiate between "normal" levels of postpartum distress and depressive symptoms that might require intervention. Talking about their distress and experiences, both with health professionals and other mothers, was regarded as of primary importance in the recovery process.

Rates of referral and treatment for women with positive screening results were substantially higher in two studies where screening, diagnosis, and treatment were provided in the same setting.
Systematic review of 40 studies 
Table 1 Summary of appraised studies that investigated barriers and facilitators to engagement with PMHS (Continued)

\begin{tabular}{|c|c|c|}
\hline Author, year, country & Study type, sample & Main findings \\
\hline $\begin{array}{l}\text { Myors et al. } 2014 \text { [23] } \\
\text { Australia }\end{array}$ & Mixed-methods study, $n=244$ perinatal women & $\begin{array}{l}\text { Results indicated there was no significant difference in the risk factors } \\
\text { for mental illness during the perinatal period in women who engagec } \\
\text { and those who did not with PMHS. The time lag between initially } \\
\text { assessment and contact by PMHS was a barrier to initial engagement. } \\
\text { Stigma was another barrier and clinicians using women led model of } \\
\text { service delivery with flexibility was more likely to be successful to } \\
\text { promote engagement. }\end{array}$ \\
\hline $\begin{array}{l}\text { Reilly et al. } 2013 \text { [24] } \\
\text { Australia }\end{array}$ & $\begin{array}{l}\text { Case control study, } n=1804 \text { drawn from the } \\
\text { Australian Longitudinal Study on Women's Health }\end{array}$ & $\begin{array}{l}\text { The odds of receiving a referral were up to } 16 \text { times greater for } \\
\text { women who were asked about both their past and current mental } \\
\text { health than for women who did not receive any form of mental } \\
\text { health assessment. }\end{array}$ \\
\hline
\end{tabular}

of consecutive, unselected women attending their first medical appointment (generally $\geq 20$ weeks gestation) were approached individually in the antenatal clinic waiting room by one of the researchers (Author 2). To prevent the perception of coercion, this researcher was not involved in the provision of healthcare to the individual, and women were advised their health care would not be influenced regardless of their decision to participate. Prior to the medical appointment women would typically have been reviewed by a midwife, completed the EPDS, provided education about $\mathrm{PD} / \mathrm{A}$ and referred to PMHS if appropriate. After being provided patient-oriented verbal and written information about the study by the approaching researcher, women who met eligibility criteria and agreed to participate were provided with a portable electronic device with access to the questionnaire in Google Forms. The researcher was readily available if women had clarification questions.

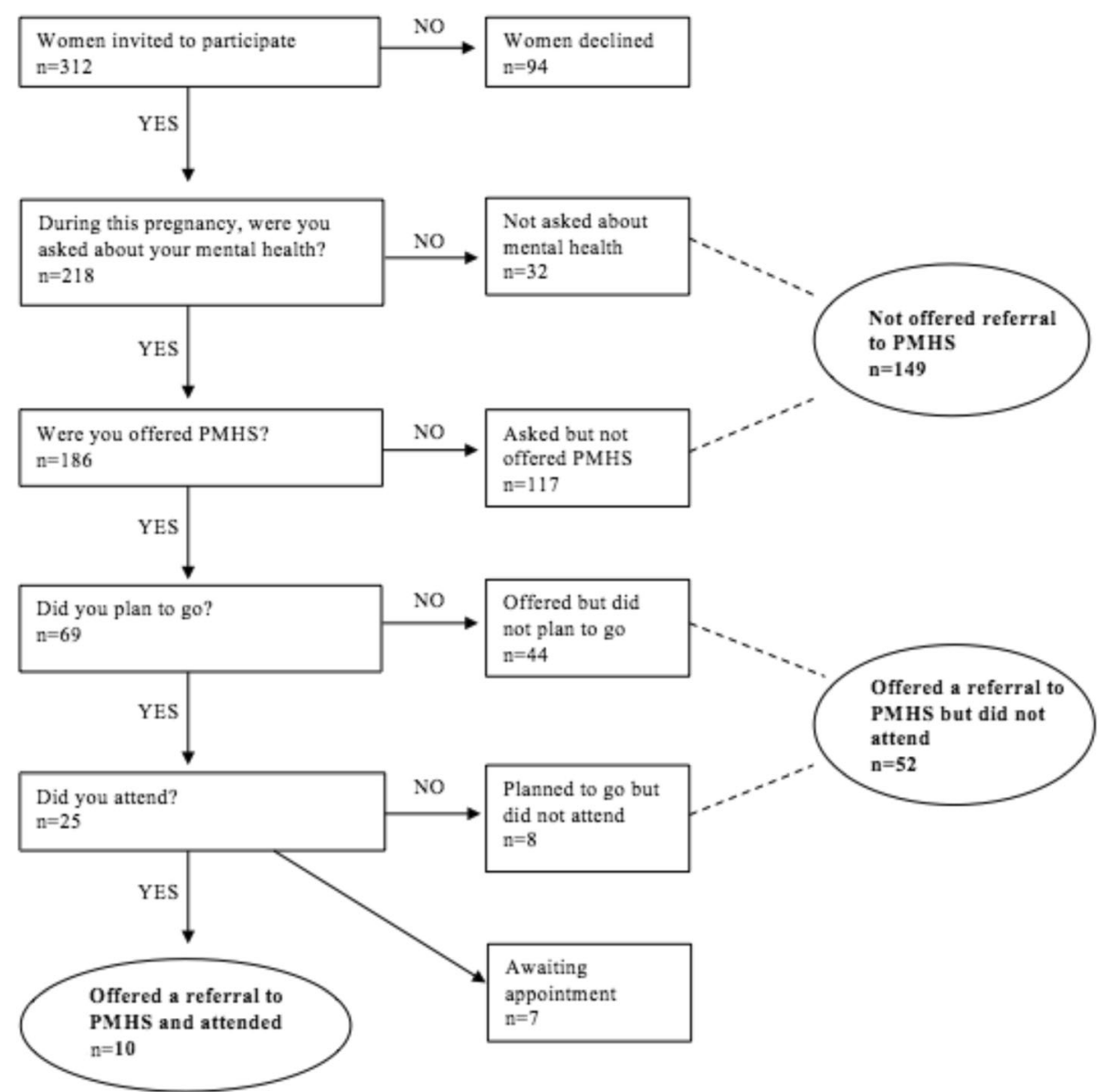

Fig. 1 Tree algorithm implemented in study design 


\section{Statistical analysis}

Statistical analysis was performed using STATA version 13 [27], which involved the calculation of descriptive statistics and comparisons of women by referral status.

For analysis, the Likert scale was collapsed into dichotomous categories for the 2 items related to knowledge of mental health: Not knowledgeable $=1$, 2, 3 and Knowledgeable = 4, 5. For the items related to barriers and facilitators, responses were also collapsed into dichotomous categories of "Not at all" and "A little"/ "A lot". The "Not applicable" response was converted to missing. The frequencies of responses for these items were concentrated at the extremes of the 3-point scale. Dichotomous categorisation of the responses for these items focused on improving the interpretability of the data.

Responses to section three of the questionnaire for women who were still waiting for their PMHS appointment and planned to attend $(n=7)$ were excluded from the analysis, as it was impossible to determine if they would have engaged with PMHS.

Responses to each question were summarised by frequency and percentage. Categorical variables were examined using the Pearson Chi-squared test, or Fisher's Exact test when more than $20 \%$ of the expected values were less than five.

\section{Results}

Questionnaires were completed by 218 of the 307 women approached giving a response rate of $71 \%$. Participant characteristics are described in Table 2. The majority of participants $(83.9 \% ; n=183)$ were aged less than 35 years; with $24.3 \%(n=53)$ aged $18-24$ and $59.6 \%(n=$ $130)$ aged 25 to 34 . Around half $(50.9 \% ; n=111)$ identified as Caucasian and 5\% $(n=11)$ identified as Aboriginal or Torres Strait Islander. Just over a quarter (28.4\%) of women reported that this was their first pregnancy.

Table 3 describes the participants' self-report of their mental health history and knowledge of mental illness. Almost half $(46.8 \% ; n=102)$ did not consider themselves to be knowledgeable about PD/A. Almost a third $(28.4 \% ; n=62)$ reported not being provided information on $\mathrm{PD} / \mathrm{A}$, and $14.7 \%(n=32)$ did not recall being asked by a HCP about their mental health during this pregnancy. More than one third $(37.6 \% ; n=82)$ self-reported being diagnosed with depression or anxiety at some time. This is in concordance with a higher than average incidence of self-reported anxiety and depression in a previous study by some of the authors [28].

Table 4 summarises the participants' referral status and engagement with PMHS. Of the participants who recall being asked about their mental health $(n=186), 69$ (37.1\%) reported being offered a referral to PMHS. Of these participants offered a referral, roughly one third (36.2\%; $n=25)$ accepted the referral, but only less than
Table 2 Participant demographics

\begin{tabular}{|c|c|}
\hline Question & $\begin{array}{l}\text { Overall }(n= \\
218)\end{array}$ \\
\hline \multicolumn{2}{|l|}{ How old are you? } \\
\hline 18 to 24 & $53(24.3 \%)$ \\
\hline 25 to 34 & $130(59.6 \%)$ \\
\hline 35 or above & $35(16.1 \%)$ \\
\hline \multicolumn{2}{|l|}{ Do you identify as any of the following? } \\
\hline Caucasian/white & $111(50.9 \%)$ \\
\hline Australasian & $39(17.9 \%)$ \\
\hline Indigenous Australian & $11(5.0 \%)$ \\
\hline Other & $57(26.1 \%)$ \\
\hline \multicolumn{2}{|l|}{ Which of these best represents your relationship status? } \\
\hline Single/Separated or divorced & $25(11.5 \%)$ \\
\hline De facto/Married/Partnered but not living together & $193(88.5 \%)$ \\
\hline \multicolumn{2}{|l|}{$\begin{array}{l}\text { Which of these best represents your level of } \\
\text { education? }\end{array}$} \\
\hline High school or equivalent & $102(46.8 \%)$ \\
\hline Post high school & $116(53.2 \%)$ \\
\hline \multicolumn{2}{|l|}{ Which of these best represents your employment status? } \\
\hline Unemployed & $96(44.0 \%)$ \\
\hline Employed & $122(56.0 \%)$ \\
\hline \multicolumn{2}{|c|}{ Which of the following is the best estimate of your household income? } \\
\hline$\$ 0-\$ 37,000$ & $59(27.1 \%)$ \\
\hline$\$ 37,001-\$ 87,000$ & $99(45.4 \%)$ \\
\hline$\$ 87,001$ and over & $60(27.5 \%)$ \\
\hline \multicolumn{2}{|l|}{ Is this your first pregnancy? } \\
\hline No & $156(71.6 \%)$ \\
\hline Yes & $62(28.4 \%)$ \\
\hline \multicolumn{2}{|l|}{ Was this a planned pregnancy? } \\
\hline No & $92(42.2 \%)$ \\
\hline Yes & 126 (57.8\%) \\
\hline
\end{tabular}

half, $40.0 \%(n=10)$ actually attended. Only 1 in 7 women, who were referred actually attended the appointment.

Participants with a self-reported history of mental illness were more likely than those without a history to be offered an appointment to PMHS $(p=0.001)$. Participants reporting previously being treated for anxiety or depression, were more likely, than those who had never received treatment $(p=0.001)$ to plan to attend the appointment.

Table 5 summarises the responses of participants to questions about the extent to which specified factors would influence their decision to engage with the PMHS.

Comparison of the factors influencing a woman's decision to engage with PMHS between groups indicated that WNOR, compared to WDNA and WA, reported they were hypothetically more likely to be influenced by the cost related to going to the appointment $(p<0.001)$, and whether 
Table 3 Participant understanding of mental health illness and history of depression and/or anxiety

\begin{tabular}{ll}
\hline Question & $\begin{array}{c}\text { Overall } \\
(n=218)\end{array}$ \\
\hline $\begin{array}{l}\text { Has a health professional ever diagnosed you with clinical depression or } \\
\text { anxiety? }\end{array}$ & 136 \\
Neither & $(62.4 \%)$ \\
& $11(5.0 \%)$ \\
Anxiety & $24(11.0 \%)$ \\
Depression & $47(21.6 \%)$ \\
Both & \\
Have you ever been treated for depression or anxiety? & 123 \\
No, I have never been diagnosed with depression and/or & $(56.4 \%)$ \\
anxiety & $13(6.0 \%)$ \\
No, but I have been diagnosed with depression and/or & \\
anxiety & $23(10.6 \%)$ \\
Yes, I am currently being treated & $83(38.1 \%)$ \\
How would you rate your knowledge of mental illness generally? & 135 \\
Not knowledgeable & $(61.9 \%)$ \\
Knowledgeable &
\end{tabular}

How would you rate your knowledge of mental illness during pregnancy and after childbirth?

Not knowledgeable

Knowledgeable

Have you been given information on perinatal depression and/or anxiety during this pregnancy?

No/Can't recall

$62(28.4 \%)$

Yes

During this pregnancy, have any health professionals asked you questions about your mental health?

No/Can't recall

it was required by the Department of Child Services $(p<$ $0.001)$. Whereas, WDNA were less influenced by their partner opposing mental health treatment $(p=0.048)$, an appointment time that suited them $(p<0.001)$, and wanting to know what help was available $(p=0.006)$.

For WDNA a lack of time, no one to look after children, and encouragement by family and HCP were identified as the primary factors that influenced their decision to not engage with PMHS. In this subpopulation, over $50.0 \%$ of participants reported these factors had "some influence" on their engagement. In WNOR the same factors were rated as likely to hypothetically influence their engagement with PMHS. Compared to WDNA and WNOR, fewer WA reported that a lack of time, no one to look after children and encouragement
Table 4 Summary of engagement with perinatal mental health services for those women who were asked about their mental health by health professionals

\begin{tabular}{lc}
\hline Question & Overall $(n=186)$ \\
\hline $\begin{array}{l}\text { After you were asked about your mental health, were you offered any } \\
\text { perinatal mental health services? }\end{array}$ & $117(62.9 \%)$ \\
No & $69(37.1 \%)$ \\
Yes & $44(63.8 \%)$ \\
After you were offered services, did you plan to go? $(n=69)$ \\
No & $25(36.2 \%)$ \\
Yes & $7(28.0 \%)$ \\
Did you attend the appointment? $(n=25)$ & $8(32.0 \%)$ \\
I'm still waiting to attend my appointment & $10(40.0 \%)$ \\
No & \\
Yes &
\end{tabular}

by family as factors influencing their decision. However, it is noted that this is not statistically significantly different from the other two groups.

\section{Discussion}

\section{Main findings}

This study illustrates the low levels of engagement with PMHS in a high-risk population with a high incidence of self-reported history of anxiety and depression and emphasises the importance of identifying barriers and facilitators to provide psychiatric assessment and appropriate management. It also expands on previous research by identifying factors influencing antenatal women's engagement with PMHS in an Australian context. These factors, regardless of women's PMHS referral status and engagement, were: (1) lack of time; (2) no one to look after their children; and, (3) encouragement by their family and HCP. Notably, stigma was not found to be a significant barrier to engagement.

This study also identified three factors that could influence service engagement: (1) at least one quarter of women did not recall being given any information about $\mathrm{PD} / \mathrm{A}$ during their pregnancy; (2) nearly $15 \%$ of women did not recall being asked about their mental health during their pregnancy; and (3) nearly half of participants did not consider themselves knowledgeable about mental illness in the perinatal period.

\section{Discussion and interpretation of main findings}

Consistent with findings of other studies, encouragement by family members and HCP were both identified as facilitating factors to women's decision to engage with PMHS regardless of their referral status [13, 29, 30]. As identified by Prevatt et al. [31], some women may choose not to openly disclose their emotional distress, as such HCP should proactively promote engagement with mental 
Table 5 Factors influencing decision to engage with perinatal mental health services

\begin{tabular}{|c|c|c|c|c|}
\hline Question & $\begin{array}{l}\text { Not offered } \\
\text { PMHS } \\
\text { Overall }(n=149)\end{array}$ & $\begin{array}{l}\text { Offered but did not } \\
\text { attend } \\
\text { Overall }(n=52)\end{array}$ & $\begin{array}{l}\text { Offered and } \\
\text { attended } \\
\text { Overall }(n=10)\end{array}$ & $p$-value \\
\hline Lack of time & & & & 0.23 \\
\hline No influence & $45(33.3 \%)$ & $16(35.6 \%)$ & $6(60.0 \%)$ & \\
\hline Some influence & $90(66.7 \%)$ & $29(64.4 \%)$ & $4(40.0 \%)$ & \\
\hline Cannot get time off work & & & & 0.098 \\
\hline No influence & $59(52.2 \%)$ & $25(71.4 \%)$ & $5(71.4 \%)$ & \\
\hline Some influence & $54(47.8 \%)$ & $10(28.6 \%)$ & $2(28.6 \%)$ & \\
\hline $\begin{array}{l}\text { No one to look after my child (ren) while I'm attending an } \\
\text { appointment }\end{array}$ & & & & 0.064 \\
\hline No influence & $48(40.3 \%)$ & $19(45.2 \%)$ & $6(85.7 \%)$ & \\
\hline Some influence & $71(59.7 \%)$ & $23(54.8 \%)$ & $1(14.3 \%)$ & \\
\hline No transport to appointment & & & & 0.46 \\
\hline No influence & $95(79.2 \%)$ & $35(87.5 \%)$ & $6(75.0 \%)$ & \\
\hline Some influence & $25(20.8 \%)$ & $5(12.5 \%)$ & $2(25.0 \%)$ & \\
\hline How long I had to wait for the appointment & & & & 0.10 \\
\hline No influence & $81(62.8 \%)$ & $32(80.0 \%)$ & $7(77.8 \%)$ & \\
\hline Some influence & $48(37.2 \%)$ & $8(20.0 \%)$ & $2(22.2 \%)$ & \\
\hline Inconvenience attending appointment & & & & 0.33 \\
\hline No influence & $81(60.9 \%)$ & $31(72.1 \%)$ & $6(75.0 \%)$ & \\
\hline Some influence & $52(39.1 \%)$ & $12(27.9 \%)$ & $2(25.0 \%)$ & \\
\hline Costs related to going to the appointment & & & & $\begin{array}{l}< \\
0.001^{*}\end{array}$ \\
\hline No influence & $63(48.1 \%)$ & $33(78.6 \%)$ & $7(87.5 \%)$ & \\
\hline Some influence & $68(51.9 \%)$ & $9(21.4 \%)$ & $1(12.5 \%)$ & \\
\hline Previous unhelpful experience with mental health services & & & & 0.074 \\
\hline No influence & $91(82.0 \%)$ & $30(69.8 \%)$ & $5(55.6 \%)$ & \\
\hline Some influence & $20(18.0 \%)$ & $13(30.2 \%)$ & $4(44.4 \%)$ & \\
\hline Partner opposed to mental health treatment & & & & $0.048^{*}$ \\
\hline No influence & $105(89.0 \%)$ & $42(100.0 \%)$ & $7(87.5 \%)$ & \\
\hline Some influence & $13(11.0 \%)$ & $0(0.0 \%)$ & $1(12.5 \%)$ & \\
\hline Not feeling motivated & & & & 0.79 \\
\hline No influence & $85(68.5 \%)$ & $27(62.8 \%)$ & $6(66.7 \%)$ & \\
\hline Some influence & 39 (31.5\%) & $16(37.2 \%)$ & $3(33.3 \%)$ & \\
\hline Concern about being judged & & & & 0.16 \\
\hline No influence & $100(80.0 \%)$ & $38(86.4 \%)$ & $6(60.0 \%)$ & \\
\hline Some influence & $25(20.0 \%)$ & $6(13.6 \%)$ & $4(40.0 \%)$ & \\
\hline Worried about your mental health & & & & 0.89 \\
\hline No influence & $74(54.8 \%)$ & $21(51.2 \%)$ & $5(50.0 \%)$ & \\
\hline Some influence & $61(45.2 \%)$ & $20(48.8 \%)$ & $5(50.0 \%)$ & \\
\hline Encouragement by family & & & & 0.55 \\
\hline No influence & $52(39.7 \%)$ & $17(45.9 \%)$ & $5(55.6 \%)$ & \\
\hline Some influence & 79 (60.3\%) & $20(54.1 \%)$ & $4(44.4 \%)$ & \\
\hline Encouraged by midwife/GP/obstetrician & & & & 0.43 \\
\hline No influence & $43(33.9 \%)$ & $17(44.7 \%)$ & $3(30.0 \%)$ & \\
\hline
\end{tabular}


Table 5 Factors influencing decision to engage with perinatal mental health services (Continued)

\begin{tabular}{|c|c|c|c|c|}
\hline Question & $\begin{array}{l}\text { Not offered } \\
\text { PMHS } \\
\text { Overall }(n=149)\end{array}$ & $\begin{array}{l}\text { Offered but did not } \\
\text { attend } \\
\text { Overall }(n=52)\end{array}$ & $\begin{array}{l}\text { Offered and } \\
\text { attended } \\
\text { Overall }(n=10)\end{array}$ & $p$-value \\
\hline Some influence & $84(66.1 \%)$ & $21(55.3 \%)$ & $7(70.0 \%)$ & \\
\hline Previous good experience with mental health services & & & & 0.16 \\
\hline No influence & $45(45.0 \%)$ & $22(62.9 \%)$ & $4(40.0 \%)$ & \\
\hline Some influence & $55(55.0 \%)$ & $13(37.1 \%)$ & $6(60.0 \%)$ & \\
\hline Required by Department of Child Services & & & & $\begin{array}{l}< \\
0.001^{*}\end{array}$ \\
\hline No influence & $49(51.0 \%)$ & $32(100.0 \%)$ & $6(100.0 \%)$ & \\
\hline Some influence & $47(49.0 \%)$ & $0(0.0 \%)$ & $0(0.0 \%)$ & \\
\hline Previously suffered from postnatal depression & & & & 0.14 \\
\hline No influence & $54(60.0 \%)$ & $24(66.7 \%)$ & $6(100.0 \%)$ & \\
\hline Some influence & $36(40.0 \%)$ & $12(33.3 \%)$ & $0(0.0 \%)$ & \\
\hline Previously suffered from other mental health issues & & & & 0.67 \\
\hline No influence & $53(53.5 \%)$ & $19(51.4 \%)$ & $4(40.0 \%)$ & \\
\hline Some influence & $46(46.5 \%)$ & $18(48.6 \%)$ & $6(60.0 \%)$ & \\
\hline An appointment time that suits me & & & & $\begin{array}{l}< \\
0.001^{*}\end{array}$ \\
\hline No influence & $46(36.5 \%)$ & $27(75.0 \%)$ & $4(44.4 \%)$ & \\
\hline Some influence & $80(63.5 \%)$ & $9(25.0 \%)$ & $5(55.6 \%)$ & \\
\hline Wanting to discuss medications & & & & 0.083 \\
\hline No influence & $63(55.8 \%)$ & $26(74.3 \%)$ & $7(77.8 \%)$ & \\
\hline Some influence & $50(44.2 \%)$ & $9(25.7 \%)$ & $2(22.2 \%)$ & \\
\hline Wanting support/counselling & & & & 0.14 \\
\hline No influence & $53(43.1 \%)$ & $23(60.5 \%)$ & $5(55.6 \%)$ & \\
\hline Some influence & $70(56.9 \%)$ & $15(39.5 \%)$ & $4(44.4 \%)$ & \\
\hline Wanting to know what help is available & & & & $0.006^{*}$ \\
\hline No influence & $52(41.6 \%)$ & $27(71.1 \%)$ & $4(44.4 \%)$ & \\
\hline Some influence & $73(58.4 \%)$ & $11(28.9 \%)$ & $5(55.6 \%)$ & \\
\hline
\end{tabular}

${ }^{*} p$-value $<0.05$

health services to all women and their social supports if there are identified risk factors or concerns about mental health/emotional wellbeing in the perinatal period.

In accordance with previous published literature, lack of access to appropriate childcare and a lack of time were identified as barriers to engagement with PMHS [13, 32]. Compared to Kim et al. [8], the rate of PMHS engagement in this study was low (50\% vs. $24 \%$ ). Button et al. [16] demonstrated that women felt they would be more likely to engage with healthcare services if childcare services could be provided. Improving immediacy and accessibility of access to PMHS could address a perceived lack of time. Byatt et al. [9] found that providing resources to women and offering on-site mental health assessments doubled the rates of engagement with PMHS compared to screening alone. Further studies identified that a short period between PMHS referral and assessment increases engagement, as some women lose interest and/or motivation [10, 18]. Therefore, health services should develop a PMHS capable of: providing timely and accessible appointments at the location of the antenatal service; offering informational resources at time of referral; and providing access to childcare for consumers attending PMHS.

The observed absence of concern about judgement as an identified barrier is inconsistent with the literature. Stigma, both from women themselves and others, has frequently been reported [11]. It has been previously established that women may choose not to disclose their distress [32], however it is unclear why stigma was not identified as a factor in this study. The exact reasons for omission are likely multifactorial and require further exploration in future studies.

A significant proportion of the cohort did not consider themselves knowledgeable about common mental illness during and after pregnancy and did not recall being 
screened for PD/A. Studies have consistently shown that lack of literacy on the topic of mental illness in the perinatal period impairs a woman's ability to identify symptoms, and therefore impacts on their engagement with PMHS [10, 11, 17]. Austin et al. [14] support active education about $\mathrm{PD} / \mathrm{A}$ to women, and repeated screening through the perinatal period. Due to the nature of the questionnaire, it is impossible to determine if women were screened for $\mathrm{PD} / \mathrm{A}$ and/or educated about $\mathrm{PD} / \mathrm{A}$. Regardless, the results suggest that women need to be proactively engaged in a meaningful experience during the screening process, and educated on the rationale for further assessment and treatment. Goldin Evans et al. [33] and Long et al. [34] found that screening rates increase if HCP are educated about perinatal mental health, emphasizing the need for health services to increase mental health literacy amongst HCP. This would also improve health literacy amongst women and their social supports, potentially facilitating increased emotional support.

\section{Strengths and limitations}

The cross-sectional questionnaire facilitated the concurrent collection of information about PMHS referral rates and engagement levels within the study population. Several strategies were used to engage women that were unlikely to engage with, or had refused to engage with, PMHS. The short questionnaire length and dissemination through personal invitation at the antenatal clinic provided a high response rate of $71 \%$. Positively, women who had declined engagement with the PMHS agreed to complete the questionnaire. The anonymous nature of the questionnaire may have increased women's willingness to answer questions truthfully.

Notably in the study sample, only 69 women were referred to PMHS and of those only 10 women had engaged with PMHS. Although the numbers were small, no significant difference was found in factors influencing this group compared to women who did not engage and women not referred to PMHS.

Limitations of the study include the inability to generalise the results to all Australian antenatal women due to self-selection of the participants through convenience sampling. There are some differences between the study population and the general population. In comparison to pregnant women in Queensland: there were a higher proportion of pregnant women under the age of 24 in the sample (24.3\% vs. $19.9 \%)$; a lower rate of employment during pregnancy $(56.0 \%$ vs. $68 \%)$; a higher background incidence of anxiety and depression (37.6\%) and a similar proportion of women identifying as Aboriginal or Torres Strait Islander (5.0\% vs 6.8\%) [35, 36]. Overall, the demographic characteristics of the sample are indicative of greater socio-economic disadvantage compared to the general population, which is consistent with what is expected for the region. However, it is noted that this limits the generalisability of results obtained to a general population of pregnant women in Australia.

Regarding the analysis of results, a limitation of the study was the collapsing of responses into dichotomous categories for some items in the questionnaire. Dichotomisation of data results in the loss of precision, however due to the distribution of results being concentrated at the extremes of the scales for some items, the loss of information from dichotomisation is compensated by the benefit of improving the interpretability of results.

Women were asked to rate pre-determined barriers and facilitators, potentially resulting in loss of key themes. The EPDS was not included in the questionnaire, and therefore it is not possible to correlate the score with the level of engagement. These omissions were consciously made to decrease the length of the questionnaire and for ease of completion.

\section{Conclusion}

In Australia, one in six maternal deaths are due to suicide [6]. Despite a clear need for mental health support during the perinatal period, engagement of women with $\mathrm{PD} / \mathrm{A}$ remains a significant challenge. The following health service practice and policy implementations could improve PMHS engagement: (1) offering women attending appointments assistance with childcare; (2) providing $\mathrm{PD} / \mathrm{A}$ informational resources at time of referral; (3) improving immediacy of and accessibility to PMHS through engagement at the antenatal service; (4) providing ongoing education to all HCP involved in the care of women in the perinatal period about perinatal mental health and the positive influence HCP have on women's engagement with PMHS; (5) active engagement of women in the screening process for PD/A, and using every encounter with $\mathrm{HCP}$ as an opportunity for education and provision of resources to women and their social supports; (6) ensuring universal screening and repeating this process for $\mathrm{PD} / \mathrm{A}$ throughout the perinatal period.

Further research into factors affecting engagement with PMHS in the Australian context is required. Qualitative studies could examine the identified factors in more detail, and identify new themes affecting engagement. Furthermore, studies evaluating the impact of the suggested service and policy implementations on engagement rates are required.

\section{Additional file}

Additional file 1: Engagement with perinatal mental health services: questionnaire. (PDF $2252 \mathrm{~kb}$ ) 


\section{Abbreviations}

EPDS: Edinburgh postnatal depression score; HCP: Healthcare professionals; PD/A: Perinatal anxiety and depression; PMHS: Perinatal mental health service; WA: Women who were offered a referral to the PMHS and attended; WDNA: Women offered referral to the PMHS who did not attend; WNOR: Women not offered referral to the PMHS

\section{Acknowledgements}

The authors would like to thank all the women who participated in this study for sharing their experiences with us. The authors also thank: the Redcliffe Hospital Maternity Department; the Metro North Perinatal Mental Health Service; Joel Dulhunty, Director of Research at Redcliffe Hospital; and Satomi Okano at the Queensland Institute of Medical Research for statistical support. The project was carried out as a part of the RANZCP Fellowship requirement.

\section{Funding}

This project was supported by a Redcliffe Hospital Private Practice Trust Fund research grant of AUD 1500. The grant was utilised for the purchase of portable electronic devices. The funding body had no role in the study design, data collection, analysis, data interpretation, or any input into the writing of the manuscript.

\section{Availability of data and materials}

The datasets generated and/or analysed during the current study are not publicly available due to the HREC not providing consent, but are available from the corresponding author on reasonable request.

\section{Authors' contributions}

$A A, R C, T M, E B, S P, G B$ and $A K$ were involved in study conception, design and questionnaire development. AA, RC, TM, GB and AK obtained funding. $A A, R C, T M$ and $A K$ were involved in data acquisition and management. EB completed statistical analysis and all authors contributed to statistical interpretation. $A A$ and $R C$ were responsible for manuscript preparation and revision. AA, RC, TM, EB, SP, GB and AK provided critical feedback on al manuscript drafts and approved the final manuscript.

\section{Ethics approval and consent to participate}

Ethics approval was granted by the relevant Hospital Human Research Ethics Committee, Brisbane, Australia on October 16th 2016 (HREC/16/QPCH/237). Informed consent was implied through independent completion and submission of the survey.

\section{Consent for publication}

Not applicable.

\section{Competing interests}

The authors declare that they have no competing interests

\section{Publisher's Note}

Springer Nature remains neutral with regard to jurisdictional claims in published maps and institutional affiliations.

\section{Author details}

'Child and Youth Mental Health Service, Child Health Queensland, South Brisbane, Queensland 4010, Australia. ${ }^{2}$ Metro North Mental Health Service, Brisbane, Queensland, Australia. ${ }^{3}$ Redcliffe Hospital, Brisbane, Australia. ${ }^{4}$ Faculty of Medicine, University of Queensland, Brisbane, Queensland Australia. ${ }^{5}$ Faculty of Health and Behavioural Sciences, University of Queensland, Brisbane, Queensland, Australia. ${ }^{6}$ School of Dentistry, University of Queensland, Brisbane, Queensland, Australia. ${ }^{7}$ Queensland Institute of Medical Research, Berghofer Medical Research Institute, Brisbane, Queensland, Australia.

Received: 24 September 2018 Accepted: 29 April 2019

\section{Published online: 14 May 2019}

\section{References}

1. Howard LM, Molyneaux E, Dennis CL, Rochat T, Stein A, Milgrom J. Nonpsychotic mental disorders in the perinatal period. Lancet. 2014;384(9956): 1775-88.
2. Buist A, Bilsztra J. The beyondblue National Postnatal Screening Program, Prevention and Early Intervention 2001-2005, Final Report, vol. 1: National Screening Program. Melbourne: Beyondblue; 2006.

3. Giardinelli $L$, Innocenti A, Benni $L$, et al. Depression and anxiety in perinatal period: prevalence and risk factors in an Italian sample. Arch Womens Ment Health. 2012:15(1):21-30.

4. Schmied V, Johnson M, Naidoo N, et al. Maternal mental health in Australia and New Zealand: a review of longitudinal studies. Women Birth. 2013;26(3):167-78.

5. Grigoriadis S, de Camps Meschino D, Barrons E, et al. Mood and anxiety disorders in a sample of Canadian perinatal women referred for psychiatric care. Arch Womens Ment Health. 2011;14(4):325-33.

6. Humphrey M, Bonello M, Chughtai A, Macaldowie A, Harris K \& Chambers G. Maternal deaths in Australia 2008-2012. Maternal deaths series no. 5. Cat no. PER 70. Canberra: Australian Institute of Health and Welfare; 2015.

7. Queensland Maternal and Perinatal Quality Council (AU). Queensland Mothers and Babies, 2014 and 2015. Brisbane: Queensland Health; 2018.

8. Kim JJ, La Porte LM, Corcoran M, Magasi S, Batza J, Silver RK. Barriers to mental health treatment among obstetric patients at risk for depression. Am J Obstet Gynecol. 2010;202(3):312 e1-5.

9. Byatt N, Levin LL, Ziedonis D, Moore Simas TA, Allison J. Enhancing participation in depression Care in Outpatient Perinatal Care Settings: a systematic review. Obstet Gynecol. 2015;126(5):1048-58.

10. Blitza J, Ericksen J, Buist A, Milgrom J. Women's experience of postnatal depression - beliefs and attitudes as barriers to care. Aust J Adv Nurs. 2010; 27(3): 11.

11. Dennis $\mathrm{CL}$, Chung-Lee L. Postpartum depression help-seeking barriers and maternal treatment preferences: a qualitative systematic review. Birth. 2006; 33(4):323-31.

12. Flynn HA, Henshaw E, O'Mahen H, Forman J. Patient perspectives on improving the depression referral processes in obstetrics settings: a qualitative study. Gen Hosp Psychiatry. 2010;32(1):9.

13. Goodman J. Women's attitudes, preferences, and perceived barriers to treatment for perinatal depression. Birth. 2009;36(1):60-9.

14. Austin MP, Highet $\mathrm{N}$, and the Expert Working Group. Mental Health Care in the Perinatal Period: Australian Clinical Practice Guideline. Melbourne: Centre of Perinatal Excellence; 2017.

15. Australian Health Minister's Advisory Council. Clinical practice guidelines: antenatal care - module 1. Canberra: Australian Government Department of Health and ageing; 2012.

16. Royal Australian and New Zealand College of Obstetricians and Gynaecologists. Mental Health Care in the Perinatal Period C-obs 48: Section 4.4. RANZCOG: Melbourne; 2018.

17. Button S, Thornton A, Lee S, Shakespeare J, Ayers S. Seeking help for perinatal psychological distress: a meta-synthesis of women's experiences. Br J Gen Pract. 2017;67(663):e692

18. Byatt N, Simas TAM, Lundquist RS, Johnson JV, Ziedonis DM. Strategies for improving perinatal depression treatment in north American outpatient obstetric settings. J Psychosom Obstet Gynecol. 2012;33(4):143-61.

19. Highet N, Stevenson AL, Purtell C, Coo S. Qualitative insights into women's personal experiences of perinatal depression and anxiety. Women Birth. 2014:27(3):179-84

20. Kopelman RC, Moel J, Mertens C, Stuart S, Arndt S, O'Hara MW. Barriers to Care for Antenatal Depression. Psychiatric services (Washington, DC). Psychiatr Serv. 2008:59(4):429.

21. McCarthy M, McMahon C. Acceptance and experience of treatment for postnatal depression in a community mental health setting. Health Care Women Int. 2008;29(6):19.

22. Myers ER, Aubuchon-Endsley N, Bastian LA, et al. Efficacy and safety of screening for postpartum depression. In: Agency for Healthcare Research and Quality. Rockville (MD): Agency for Healthcare Research and Quality: U. S. Department of Health and Human Services. Comparative effectiveness reviews, no. 106.; 2013

23. Myors KA, Johnson M, Cleary M, Chmeid V. Engaging women at risk for poor perinatal mental health outcomes: a mixed methods study. Int J Ment Health Nurs. 2015;24(3):241-52.

24. Reilly N, Harris S, Loxton D, et al. Referral for management of emotional health issues during the perinatal period: does mental health assessment make a difference? Birth. 2013:40(4):297-306.

25. Census of population and housing. Canberra: Australian Bureau of Statistics 2011. https://www.abs.gov.au/websitedbs/censushome.nsf/home/ historicaldata2011?opendocument\&navpos=280. Accessed 26 Feb 2019 
26. Population by age and sex. Canberra: Australian Bureau of Statistics 2016. www.abs.gov.au/websitedbs/censushome.nsf/home/2016 [Accessed 26 Feb. 2019].

27. StataCorp. Stata Statistical Software: Release 13. College Station: StataCorp LP; 2013.

28. Kothari A, de Laat J, Dulhunty J, Bruxner G. Perceptions of pregnant women regarding use of antidepressant and anxiolytic drugs in pregnancy. Australas Psychiatry. 2018. https://doi.org/10.1177/1039856218810162 Accessed 26 Feb. 2019

29. Buist A, Bilszta J, Milgrom J, Barnett B, Hayes B, Austin MP. Health professional's knowledge and awareness of perinatal depression: results of a national survey. Women Birth. 2006;19(1):11-6.

30. Vogel D, Wade NH, Hackler A. Perceived public stigma and the willingness to seek counseling: the mediating roles of self-stigma and attitudes toward counseling. J Couns Psychol. 2007:54(1):40-50

31. Prevatt B-S, Desmarais SL. Facilitators and barriers to disclosure of postpartum mood disorder symptoms to a healthcare provider. Matern Child Health J. 2018;22(1):120-9.

32. National Instutite for health and welfare (GB). Antenatal and postnatal mental health: clinical management and service guidance. NICE: London; 2015.

33. Goldin Evans M, Phillippi S, Gee RE. Examining the screening practices of physicians for postpartum depression: implications for improving health outcomes. Womens Health Issues. 2015;25(6):703-10.

34. Long MM, Cramer RJ, Jenkins J, Bennington L, Paulson JF. A systematic review of interventions for healthcare professionals to improve screening and referral for perinatal mood and anxiety disorders. Arch Womens Ment Health. 2018;22(1):25-36.

35. Pregnancy and Employment Transitions, 2011. Canberra: Australian Bureau of Statistics.

36. Queensland Perinatal Statistics 2016. Brisbane: Queensland Health; 2016.

Ready to submit your research? Choose BMC and benefit from:

- fast, convenient online submission

- thorough peer review by experienced researchers in your field

- rapid publication on acceptance

- support for research data, including large and complex data types

- gold Open Access which fosters wider collaboration and increased citations

- maximum visibility for your research: over $100 \mathrm{M}$ website views per year

At $\mathrm{BMC}$, research is always in progress.

Learn more biomedcentral.com/submissions 